\title{
Does Affect Matter in Naturalistic Decision Making?
}

\author{
Kathleen L. Mosier \\ San Francisco State University \\ kmosier@sfsu.edu
}

\author{
Ute M. Fischer \\ Georgia Institute of Technology \\ ute.fischer@gatech.edu
}

\begin{abstract}
Motivation - Research over the past 10-15 years, however, has greatly enhanced our understanding of the ways in which affect or emotion influences how people make decisions, how they process information, how they interact with automation and computers, how they respond to risk, and which outcomes they prefer. Research approach - The purpose of this presentation is to review relevant aspects of the literature on affect and decision making, and to make the argument that NDM researchers need to be cognizant of the potential impact of affect on decision processes. Originality/Value - This presentation gives new insight to the field of Naturalistic Decision Making, which has typically assumed a 'cold' cognitive model and non-emotional, valence neutral cues and information. Take away message - We argue that NDM researchers can describe and predict expert decision making only when they have examined the role of affect and taken it into account.
\end{abstract}

\section{KEYWORDS}

Affect, incidental affect, integral affect, expertise, naturalistic decision making

\section{INTRODUCTION}

Judgment and Decision-Making research during the past two decades provides overwhelming evidence that people's judgments and decisions are critically influenced by emotions they experience at the time of decision making. How people respond to a situation -for instance, whether they are more or less risk-taking, or prefer punitive to lenient measures - has been shown to vary by their mood. Similarly, affect has been found to determine people's cognitive strategies; that is, whether they are systematic in their decision making or rely on heuristic cues.

It is surprising that research on naturalistic decision making has so far been virtually silent on the issue of emotions. This is an unfortunate knowledge gap. It seems we as researchers simply took it for granted that emotions have no place in expert decision making. The underlying assumption apparently has been that experts by virtue of their expertise are protected from the influence of emotions and base their decisions squarely on objective assessment of the situation via cues, procedures, or patterns. While this is one possibility, the role of affect in expert decision making may be more complex.

\section{BACKGROUND: AFFECT AND DECISION MAKING}

An important distinction drawn by emotions researchers is between integral affect and incidental affect. Integral affect concerns emotional responses that are elicited by the decision situation itself or its potential consequences. While these responses may stem from numerous aspects of the task context, it usually has been operationalized in terms of pleasantness or unpleasantness of the task, or effort required. Luce, Bettman, and Payne (1997), for example, gave participants the task of choosing which of a group of children would receive aid. The more difficult the task, in terms of tradeoffs and limited resources, the more negative affect was exhibited by participants and the more extensive was their processing. In contrast, Garbarino and Edell (1997) found that negative affect in response to increased cognitive effort biased participants to favor the less challenging option. Researchers have also elicited positive or negative integral affect by varying the framing of the decision task. Dunegan (1993), for example, framed hypothetical team performance as either positive (30 of 50 successful) or negative (20 of 50 unsuccessful), and observed differences in processing as a function of positive or negative framing.

Incidental affect refers to emotions that an individual brings to the decision situation and that are unconnected to the task at hand. The effect of incidental affect is usually studied by employing some variant of the emotion induction procedure. Prior to the decision task, individuals are asked to participate in an unrelated task, often entailing the recall of pleasant or unpleasant memories. Even when the independence of the tasks is stressed, emotions evoked by the first task carry over to the subsequent decision task. Several studies have demonstrated that the impact of incidental emotion is both unconscious (e.g., Forgas, 1998) and difficult to put aside, even when participants are given incentives to ignore irrelevant influences (e.g., Lerner, Small, \& Loewenstein, 2003; Lerner \& Tiedens, 2006). Research, in particular by Lerner and Keltner $(2000 ; 2001)$, further refined our understanding of the impact of incidental affect. They were able to 
show that emotions have a more differential impact on decision making than is suggested by the traditional distinction between positive and negative valence. Anger and sadness, for example, are associated with risk-seeking behaviors (Lerner \& Keltner, 2001; Raghunathan \& Pham, 1999), while positive affect as well as fear and anxiety are associated with risk-aversive choices (Isen, Nygren, \& Ashby, 1988; Lerner \& Keltner, 2001; Lerner \& Tiedens, 2006).

\section{THEORIES OF AFFECT AND DECISION MAKING}

Several different theoretical explanations have been put forth to account for the impact of emotion on decision making. Affect as information approaches suggest that decision makers use their affective state as information in their judgment process (Slovic, Finucane, Peters, \& Mac Gregor, 2002; Peters, Västfjäll, Gärling, \& Slovic, 2006; Slovic \& Peters, 2006). Feelings of happiness, for example, signal that one has sufficient information, and that the situation is benign and requires little cognitive effort; feelings of fear or anxiety signal that the situation is threatening in some way and requires more scrutiny, that is, systematic processing (e.g., Schwarz, 2001; 2002; Schwarz \& Clore, 2003).

Affect has also been posited to function in a two-step process, as described by the Appraisal Tendency Framework (ATF). According to this model emotions are characterized by specific appraisal patterns (Smith \& Ellsworth, 1985; Ellsworth \& Scherer, 2003) and motivate individuals toward specific goals and behaviors or "action tendencies" (Chen \& Bargh, 1999; Frijda, 1986; Frijda, Kuipers, \& ter Schure, 1989; Lerner \& Keltner, 2001; Lerner \& Tiedens, 2006). Anger, for example, is experienced when an event is appraised as negative and unfair, when someone is perceived as responsible for this negative event and oneself as able to take steps towards retribution. These appraisals will induce risk-taking behavior, actions to change the situation, and an inclination to redress injustice, and to punish the perpetrator (see Lerner \& Tiedens, 2006, for a review). Gault and Sabini (2000), for instance, found that anger-induced subjects responded to a toxic waste dumping scenario with greater support for agent-punishing goals relative to reparative or preventive goals. Fear, in contrast, has been associated with the appraisal of situational control and outcome uncertainty and triggers the goals of uncertainty reduction, self-protection, and preventing harm (e.g., Nabi, 2003; Raghunathan \& Pham, 1999).

\section{AFFECT AND PROCESSING STYLE}

Perhaps the most critical influence of affect is as a motivator of information processing and behavior (Peters et al, 2006). In this function, affect may encourage decision makers toward information processing strategies that preserve positive and avoid negative experiences (e.g., Isen et al., 1988). Information that is congruent with one's mood may be more attended to, more believable, and more compelling (DeSteno, Petty, Rucker, Wegner, \& Braverman, 2004). Affect is also associated with heuristic or systematic processing styles (e.g., Bodenhausen, Sheppard, \& Kramer, 1994; Forgas, 2003; Schwarz, 2001). Anger is consistently linked with heuristic processing; that is, with more stereotypic judgments, less attention to the quality of arguments and more attention to superficial cues (e.g., Bodenhausen, Sheppard, \& Kramer, 1994; Lerner \& Tiedens, 2006). Fear or anxiety, in contrast, is believed to lead to systematic and comprehensive information processing (Loewenstein \& Lerner, 2003). Positive affect has been found to foster quicker, more superficial and less effortful strategies using little information, but also to produce more creative, open, and inclusive thought (Estrada, Isen, \& Young, 1997; Fredrickson, 2001; Isen, 1984; Isen \& Labroo, 2003).

\section{IMPLICATIONS FOR NDM PHENOMENA}

Research on affect and information processing suggests two different types of impact on decision making in dynamic environments. First, affect may limit -and thus bias-information search. Lerner and Tiedens (2006) posit that emotional states may prompt differential attention to information based on whether or not it is mood-congruent. Consistent with this notion, Nabi (2003) found that participants who were prompted to anger desired retributive information, and those in the fear group desired protection-related information.

Affect may also set a frame for coherence, and thus guide the integration of information and cues for situation assessment. That is, individuals may examine most or all of the information available to them, but the patterns identified and the rationale for their decisions will be constructed around affect-congruent themes. Ambiguous information will be interpreted in an affect-consistent manner, and inconsistent cues will be explained away, deemphasized, or discounted. Additionally, if a situation is ambiguous with respect to some critical aspect (e.g., certainty of outcome), then incidental emotion (e.g., fear) will impact decision making more (e.g., risk avoidance) as compared to unambiguous situations (Lerner \& Keltner, 2001).

Each of these modes of influence has specific implications for operational phenomena having to do with automation and computers, such as automation bias, attentional tunneling, and automation-induced complacency, all of which have been found in experts, and which entail curtailed information search in decision making. For example, automation bias refers to errors that occur when decision makers use automation as a heuristic replacement for vigilant information seeking and processing (Mosier, Skitka, Heers, \& Burdick, 1998; Skitka, Mosier, \& Burdick, 1999). Emotions such as 
anger or happiness that foster reliance on heuristics may exacerbate this phenomenon. Decision makers in these states may "recognize" a situation prematurely, or may base actions on a subset of cues and information. On the other hand, affective feelings that elicit systematic processing, such as fear or anxiety, may moderate automation bias - or may produce an opposite and potentially just as negative a strategy, namely hypervigilant attention to all available data, whether relevant or not. A similar influence may occur for attentional tunneling, the allocation of attention to a particular channel of information at the cost of other sources of information (e.g., Wickens, 2000). The tendency toward automation-induced complacency, or over-dependence on automation that has functioned safely in the past (Parasuraman, Molloy, \& Singh, 1993), might be heightened by positive affect, in that decision makers will be reluctant to seek out any information that might interfere with the positive mood.

Affect may also impact the interpretation of information in the operational context. Decision makers who are influenced by particular affective states may lock on to situation interpretations and action modes that are congruent with that state. Anger, for example, is associated with the perception of personal control over a situation, whereas fear and anxiety are associated with the perception that a situation is not under one's control. Anger may encourage a 'blame' mode, in which decision makers focus on responsibility and retribution rather than problem solving. Fear or anxiety, in contrast, may elicit an almost hypervigilant concern for self-protection and safety.

\section{EXPERTISE AND AFFECT}

Does affect play a role in expert decision making? One could argue that experts making domain-related decisions should be immune to the impact of affect. Experts know, so the argument goes, what to look for, what cues are relevant to the decision, which information to obtain, and which rules and procedures to call upon. They have learned to cope with task complexity and task-related stress. Moreover, when making domain-related decisions, experts are likely to be imbued with a sense of accountability for their decisions (Mosier et al., 1998) and should engage in motivated processing (e.g., the goal to maintain flight safety). Thus affect should not influence their judgment and decision making (Forgas, 2003). In fact, proponents of this argument would explain, it is a defining characteristic of experts that they can push irrelevant information aside. The same proponents would argue that there is no place for emotions in expert decision making.

This position is short-sighted insofar as it overlooks the important distinction between incidental or task-irrelevant affect and task-integral affect. This distinction is critical to a discussion of affect in expert decision making because experts have been shown to be selectively sensitive to task critical information (c.f., Chi, Glaser, \& Farr, 1988). Accordingly, experts unlike laypersons may differentially respond to incidental and integral affect. Experts may be able to identify emotional responses that are not relevant to the task at hand and thus prevent them from impacting their decision making. On the other hand, they may be well attuned to affect that is in response to elements of the task context and that may have significance for their decisions. That is, for experts, affective reactions to situations (i.e., integral affective responses) may represent a knowledge-based informational cue, and may be a salient component of their decision making. As an illustration, consider the following quotes from a study by Fischer, Orasanu, and Davison (2003) in which commercial pilots verbalized their thoughts during hypothetical aviation decision scenarios. The first two quotes are by pilots in response to a potential windshear situation at takeoff. The last quote occurred in response to an approach scenario. (Italics added for illustration purposes.)

Subject 24 (F/O): "See whether ATIS has anything, or Tower reports. <receives ATIS and reads> "moderate rain" now start seeing some effect of that, the runway is grooved as you showed me earlier, temperature is 15 degrees, dew point is 13, 2989 altimeter, departing $36 \mathrm{~L}$ or R. Ahm. Still, starting to get close, starting to get into my comfort zone."

Subject 8 (CA): "Well, I tell the passengers that that I made a decision not to take off because of the weather and that ah other pilots may chose to go but my level of ah my level of comfort ah was exceeded by the way the thunderstorm is coming to the airport"

Subject 33 (CA): “Ahm at this point I think I'd be getting pretty concerned about my fuel situation, real concerned, and I'd be talking to dispatcher and asking for ahm feedback from them and see where they want us to go cause now I am thinking I don't even want to fool with this airport anymore at this point because if they got thunderstorms in the area we've got traffic problems ahm I'm not comfortable with 11 thousand pounds of fuel on my airplane (...) I'm totally in a divert mode I wanna go somewhere else already. I don't like this ahm I don't like the fact that even though the weather is going to clear up that there's still a bunch of airplanes out here to get on the ground....

In these scenarios, pilots apparently used their affective reactions to decision-relevant information as input to their decision making. Similarly, Dominguez (2001) reports that physicians frequently referred to their comfort level while deciding on whether or not to continue with laparoscopic surgery. Observations like these suggest that professionals are sensitive to task-integral affect and incorporate it into their decision process. 


\section{THE NEED FOR RESEARCH}

While suggestive, the above observations need to be substantiated by further research into the role of integral affect in expert decision making. More specifically research needs to address the following issues: To what extent do professionals rely on their affective reactions to task-relevant information? How does integral affect impact their decision process? Does affect serve as a frame that guides the integration of available information and cues, resulting in affect-consistent interpretations and decisions? Or, does it limit their information search to only a few cues, leading to biased decisions? Do specific emotions, such as anger or fear, influence experts' decision process in specific ways? Moreover, we need to examine whether experts do indeed respond differentially to integral and incidental affect - that is, do they integrate the former into their decision making while disregarding the latter? For instance, research by Estrada et al. (1997) indicates that experts may not always succeed in recognizing incidental affect. They found that inducing positive affect with a small package of candy significantly influenced physicians' diagnostic processing.

Research addressing the role of affect in expert decision making could also address some shortcomings of the current emotion literature, most notably by highlighting the value of affective information. While JDM researchers acknowledge the evolutionary benefit of affect, their studies almost exclusively concern incidental affect, that is, affect that is irrelevant to the task at hand and thus conflicting with sound decision making. Considerably fewer studies focus on the impact of integral affect. Moreover, when integral affect is examined, it is usually manipulated through aspects of the task that bear little substantive relation to the decision objective. That is, integral affect as it is commonly operationalized does not seem to be significantly different from incidental affect. By turning our attention to experts' use of affective information, we come to a better understanding of what it means for affect to be task-relevant and when affect should be an integral part of experts' decision making.

\section{REFERENCES}

Bodenhausen, G. V., Sheppard, L. A., \& Kramer, G. P. (1994). Negative affect and social judgment: The differential impact of anger and sadness. European Journal of Social Psychology, 24, 45-62.

Chen, M., \& Bargh, J. A. (1999). Consequences of automatic evaluation: Immediate behavioral predispositions to approach or avoid the stimulus. Personality and Social Psychology Bulletin, 25(2), 214-224.

Chi, M. T. H., Glaser, R., Farr, M. J. (1988). The nature of expertise. Hillsdale, NJ: Erlbaum Associates.

DeSteno, D., Petty, R. E., Rucker, D. D., Wegener, D. T., \& Braverman, J. (2004). Discrete emotions and persuasion: The role of emotion-induced expectancies. Journal of Personality and Social Psychology, 86, 43-56.

Dominguez, C. O. (2001). Expertise and Metacognition in Laparoscopic Surgery: A field study. Proceedings of the Human Factors and Ergonomic Society 45th Annual Meeting, Minneapolis/St. Paul, 1298-1303.

Dunegan, K. J. (1993). Framing, cognitive modes, and image theory: Toward an understanding of a glass half full. Journal of Applied Psychology, 78(3), 491-503.

Ellsworth, P. C., \& Scherer, K. R. (2003). Appraisal processes in emotion. In R. J. Davidson, K. R. Scherer, \& H. H. Goldsmith (Eds.), Handbook of affective sciences (pp. 572-595). New York, NY, US: Oxford University Press.

Estrada, C.A., Isen, A.M., \& Young, M.J. (1997). Positive Affect Facilitates Integration of Information and Decreases Anchoring in Reasoning among Physicians. Organizational Behavior and Human Decision Processes, 72(1), 117135 .

Fischer, U., Orasanu, J. \& Davison, J. (2003). Risk perception in aviation decision making: Results from a think aloud study. Poster presented at the $6^{\text {th }}$ Naturalistic Decision Making Conference, Pensacola, FL., May 2003.

Fischer, U., Orasanu, J., \& Montalvo, M. (1993). Efficient decision strategies on the flight deck. In Proceedings of the $7^{\text {th }}$ International Symposium on Aviation Psychology. Columbus, $\mathrm{OH}$.

Forgas, J., P. (1998). On being happy and mistaken: Mood effects on the fundamental attribution error. Journal of Personality and Social Psychology, 75(2), 318-331.

Forgas, J. P. (2003). Affective influences on attitudes and judgments. In R. J. Davidson, K. R. Scherer, \& H. H. Goldsmith (Eds.), Handbook of affective sciences (pp. 596-618). New York, NY, US: Oxford University Press.

Forgas, J. P., \& Locke, J. (2005). Affective influences on causal inferences: The effects of mood on attributions for positive and negative interpersonal episodes. Cognition \& Emotion, 19(7), 1071-1081. 
Fredrickson, B. L. (2001). The role of positive emotions in positive psychology: The broaden-and-build theory of positive emotions. American Psychologist, 56(3), 218-226.

Frijda, N. H. (1986). The emotions. London: Cambridge University Press.

Frijda, N. H., Kuipers, P. \& ter Schure, E. (1989). Relations among emotion, appraisal, and emotion action readiness. Journal of Personality and Social Psychology, 57(2), 212-228.

Garbarino, E. C., \& Edell, J. A. (1997). Cognitive effort, affect, and choice. Journal of Consumer Research, 24(2), $147-158$.

Gault, B. A., \& Sabini, J. (2000). The roles of empathy, anger, and gender in predicting attitudes toward punitive, reparative, and preventative public policies. Cognition and Emotion, 14, 495-520.

Isen, A. M. (1984). Toward understanding the role of affect in cognition. In R. S. Wyer, Jr., \& T.K. Srull (Eds.), Handbook of social cognition (Vol. 3, pp. 179-236). Hillsdale, NJ: Erlbaum.

Isen, A. M., \& Labroo, A. A. (2003). Some ways in which positive affect facilitates decision making and judgment. In S. L. Schneider \& J. Shanteau (Eds.), Emerging perspectives on judgment and decision research (pp. 365-393). Cambridge, UK: Cambridge University Press.

Isen, A., M., Nygren, T., E., \& Ashby, F. G. (1988). Influence of positive affect on the subjective utility of gains and losses - it is just not worth the risk. Journal of Personality and Social Psychology, 55(5), 710-717.

Klein, G. A. (1993). A recognition primed decision (RPD) model of rapid decision making. In G. A. Klein, J. Orasanu, R. Calderwood, \& C. E. Zsambok (Eds.). Decision making in action: Models and methods (pp. 138-147). Norwood, NJ: Ablex.

Klein, G. A. (2000). Sources of power: How people make decisions. Cambridge, MA: The MIT Press.

Lerner, J., S., \& Keltner, D. (2000). Beyond valence: Toward a model of emotion-specific influences on judgment and choice. Cognition \& Emotion, 14(4), 473-493.

Lerner, J. S., \& Keltner, D. (2001). Fear, anger, and risk. Journal of Personality and Social Psychology, 81(1), 146159.

Lerner, J. S., Small, D. A., \& Loewenstein, G. (2004). Heart strings and purse strings: Effects of emotions on economic transactions. Psychological Science, 15, 337-341.

Lerner, S., \& Tiedens, Z. (2006). Portrait of the angry decision maker: How appraisal tendencies shape anger's influence on cognition. Journal of Behavioral Decision Making, 19(2), 115-137.

Loewenstein, G. F., \& Lerner, J. S. (2003). The role of affect in decision making. In R. J. Davidson, K. R. Scherer, \& H. H. Goldsmith, (Eds.), Handbook of affective sciences (pp. 619-642). New York, NY, US: Oxford University Press.

Luce, M. F., Bettman, J. R., \& Payne, J. W. (1997). Choice processing in emotionally difficult decisions. Journal of Experimental Psychology: Learning, Memory, and Cognition, 23(2), 384-405.

Mosier, K. L., Skitka, L. J., Heers, S., \& Burdick, M. D. (1998). Automation bias: Decision making and performance in high-tech cockpits. International Journal of Aviation Psychology, 8, 47-63.

Nabi, R., L. (2003). Exploring the framing effects of emotion: Do discrete emotions differentially influence information accessibility, information seeking, and policy preference? Communication Research, 30(2), 224-247.

Orasanu, J., \& Strauch, B. (1994). Temporal factors in aviation decision making. Proceedings of the Human Factors and Ergonomics Society Meeting (pp. 935-939). Santa Monica, CA: HFES.

Parasuraman, R. M., Molloy, R., \& Singh I. L. (1993). Performance consequences of automation induced" complacency.” International Journal of Aviation Psychology, 3, 1-23.

Peters, E., Västfjäll, D., \& Gärling, T., \& Slovic, P. (2006). The role of affect in decision-making. A hot topic. Journal of Behavioral Decision Making, 19(2), 79-85.

Raghunathan, R., \& Pham, M. T. (1999). All negative moods are not equal: Motivational influences of anxiety and sadness on decision making. Organizational Behavior and Human Decision Processes, 70(1), 56-77.

Schwarz, N. (2001). Feelings as information: Implications for affective influences on information processing. In L. L. Martin \& G. L. Clore (Eds.), Theories of mood and cognition: A user's handbook (pp. 159-176). Mahwah, NJ: Lawrence Erlbaum Associates. 
Schwarz, N. (2002). Feelings as information: Moods influence judgments and processing strategies. In T. Gilovich, D. Griffin, \& D. Kahneman (Eds.), Heuristics and biases: The psychology of intuitive judgment (pp. 534-547). New York, NY, US: Cambridge University Press.

Schwarz, N., \& Clore, G. L. (2003), Mood as information: 20 years later. Psychological Inquiry, 13(3-4), $296-303$.

Skitka, L. J., Mosier, K. L., \& Burdick, M. (1999). Does automation bias decision making? International Journal of Human-Computer Studies 50, 991-1006.

Slovic, P., Finucane, M., Peters, E., \& MacGregor, D. G. (2002). The affect heuristic. In T. Gilovich, D. Griffin, \& D. Kahneman (Eds.), Heuristics and biases: The psychology of intuitive judgment (pp. 397-420). New York, NY, US: Cambridge University Press.

Slovic, P., \& Peters, E. (2006). Risk perception and affect. Current Directions in Psychological Science, 15(6), 322325.

Smith, C. A., \& Ellsworth, P. C. (1985). Patterns of cognitive appraisal in emotion. Journal of Personality and Social Psychology, 48(4), 813-838.

Wickens, C. D. (2000). Imperfect and unreliable automation and its implications for attention allocation, information access and situation awareness (Final Technical Report ARL-00-10/NASA-00-2). Savoy, IL: University of Illinois, Aviation Research Laboratory. 